\title{
G protein gene variants in schizophrenia
}

\author{
Hatice HumeYra Yavuz GoKce ${ }^{1}$ \\ https://orcid.org/0000-0002-7598-6690 \\ SELCUK DASDEMIR ${ }^{2}$ \\ https://orcid.org/0000-0002-7816-8909 \\ CEM Ismail KucuKaLI ${ }^{3}$ \\ https://orcid.org/0000-0001-9851-8577 \\ ELIF SINEM IPLIK \\ https://orcid.org/0000-0003-3465-1808 \\ Bedia CAKMakoglu 1 \\ https://orcid.org/0000-0001-7960-9131 \\ 1 Department of Molecular Medicine, Aziz Sancar Institute of Experimental Medicine, Istanbul University, Istanbul, Turkey. \\ 2 Department of Medical Biology, Faculty of Medicine, Istanbul University, Istanbul, Turkey. \\ ${ }^{3}$ Department of Neuroscience, Aziz Sancar Institute of Experimental Medicine, Istanbul University, Istanbul, Turkey. \\ ${ }^{4}$ Department of Biochemistry, Faculty of Pharmacy, Istanbul Yeni Yuzyil University, Istanbul, Turkey.
}

Received: 03/05/2019 - Accepted: 11/04/2019

DOI: 10.1590/0101-60830000000227

\begin{abstract}
Background: Various studies demonstrating enhanced vulnerability to apoptosis may contribute to the pathobiology of schizophrenia. Objective: Thus, G proteins may provide an intriguing link between the signal transduction, and apoptotic hypotheses of schizophrenia. In the light of these findings, we investigated whether G protein gene polymorphisms (GNAS1-T393C and GNB3-C825T) accounted for an increased risk of schizophrenia. Methods: The present analyses were based on 100 subjects diagnosed with schizophrenia, and on 100 unrelated healthy controls. The genotyping of GNAS1-T393C, and GNB3-C825T gene polymorphisms were performed using the polymerase chain reaction- restriction fragment length polymorphism (PCR-RFLP). Results: We demonstrated the positive association of GNB3-C825T gene variants with schizophrenia risk (p: 0.023). In our study, more prevalent CC genotype frequencies were detected in GNB3 in patients compared with the frequencies in the controls. The individuals with GNB3-C825T CC genotype had 2 fold increased risk for schizophrenia (p: 0.011, $\chi^{2}: 6.39$, OR:2.14,95\% CI: 1.18-3.90). Discussion: Our study results suggested that GNB3-C825T polymorphism might be associated with schizophrenia.
\end{abstract}

Gokce Yavuz HH et al. / Arch Clin Psychiatry. 2020;47(2):31-4

Keywords: G protein, GNB3, GNAS1, schizophrenia, polymorphisms.

\section{Introduction}

Schizophrenia is a common psychiatric illness that is characterized by psychotic phenomena such as delusions, hallucinations, and thought disorder, along with impairment in emotions and social function ${ }^{1}$. The lifetime morbidity risk is approximately $1 \%$ in schizophrenia ${ }^{2}$. Schizophrenia is a complex biological disorder whose pathogenesis is likely to be governed by a number of different risk factors. It is well-established that the heritability of schizophrenia was over $80 \%{ }^{1,2}$. Family, twin, and adoption studies over the past century strongly indicated that predisposition is largely genetically determined. Several environmental risk factors such as perinatal viral infections, obstetric trauma, and maternal malnutrition have been identified as risk factors for schizophrenia ${ }^{3}$. The prevalence of schizophrenia is similar among men, and women ${ }^{4}$. However, the course of schizophrenia is often more severe in men with earlier onset of the disease ${ }^{5}$. The diagnosis relies on clinical observation and self-reports because there is no available diagnostic laboratory tests for schizophrenia.

Heterotrimeric guanine nucleotide binding proteins ( $\mathrm{G}$ proteins) play key roles in the conversion of external receptor signals into intracellular response. $\mathrm{G}$ proteins are composed of $\mathrm{a}, \mathrm{b}$, and $\mathrm{g}$ subunits, and each subunit is coded by various different genes ${ }^{6}$. Many studies showed that the dysregulation of neurotransmitters signal transduction pathways ${ }^{7}$, and enhanced vulnerability to apoptosis may both contribute to the pathobiology of the schizophrenia ${ }^{8}$. Thus, $\mathrm{G}$ proteins may provide an intriguing link between the signal transduction, and apoptotic hypotheses of schizophrenia. In an animal study, a $\mathrm{G}$ protein signaling gene knockout or mutant mice has been reported to develop abnormal involuntary movements 9 . In addition, G-protein measurements were suggested to be a biochemical marker for schizophrenia ${ }^{10}$.

The synonymous T393C polymorphism in the GNAS1 gene was reported to be possibly significantly affect Gas mRNA expression, with TT genotypes displaying highest Gas expression and greater apoptotic vulnerability in several different cell types ${ }^{11}$. The GNB3 gene codes the b-subunit 3 of G-proteins, and (GNB3) C825T polymorphism (T-allele) results in increased intracellular signal transduction in G-protein coupled receptors ${ }^{12}$. The T-allele results in an in-frame deletion of 41 amino acids, and has been associated with major depression ${ }^{13}$. Moreover, the $\mathrm{C} / \mathrm{T}$ or $\mathrm{T} / \mathrm{T}$ genotype has been reported to be associated with seasonal affective disorder ${ }^{14}$.

The aim of the present study was to investigate the possible association between GNB3-C825T and GNAS1-T393C polymorphisms with the presence of schizophrenia.

\section{Material and methods}

\section{Subject selection}

The study sample comprised of 100 patients with schizophrenia, and 100 healthy controls with no personal or family history of psychiatric disorders. All patients had psychotic or active symptoms at the time of the study. Most patients were receiving antipsychotic medication at the time of scan. Each patient was given a diagnostic assessment based on the clinical interviews using a Structured Clinical Interview for Diagnostic and Statistical Manual of Mental Disorders, Fourth Edition (DSM-IV) ${ }^{15}$. The mean age was $41.25 \pm 10.98$ years for 
schizophrenia patients, and $40.54 \pm 12.83$ years for controls. No significant difference was detected between the study, and control groups in terms of mean age and sex distribution.

To minimize the effect of ethnic differences in gene frequencies, the study participants were selected among the Turkish population living in the western region of Turkey. The study was approved by the Medical Ethics Committee of Istanbul Medical Faculty, and all participants (i.e. controls, patients or unaffected family members (on behalf of some patients) gave written informed consents.

\section{Measurements, protocol and procedure}

All subjects were examined in accordance with a standardized interview, and examination. Assessment was done using a form which required patient information regarding demographic and personal details of the patients and informants, symptoms of the patients, history of present illness, details of medical or surgical interventions, past history, family history, personal history, premorbid personality, details of physical examination, mental status examination, and the diagnostic formulation. The diagnosis was made using a Structured Clinical Interview for DSM-IV (SCID-I) ${ }^{16}$. The patients were then screened on various rating scales like Brief Psychiatric Rating Scale ${ }^{17,18}$ for patients with schizophrenia, Scale for the Assessment of Positive Symptoms (SAPS) ${ }^{19}$ and Scale for the Assessment of Negative Symptoms (SANS) ${ }^{19}$ for patients with schizophrenia. The subtypes of schizophrenia patients were classified in accordance with the DSM-IV. Relatives and controls with schizophrenia were excluded from the study using the Structured Clinical Interview for DSM-IV16. Healthy and unrelated volunteers with no psychiatric disorders were selected as the control group. Control group and first-degree relatives of schizophrenia patients were screened using the Schedule for Affective Disorders and Schizophrenia-Lifetime Version ${ }^{20,21}$.

\section{Inclusion and exclusion criteria}

The patients diagnosed with schizophrenia in accordance with the DSM-IV were included in the study. Patients diagnosed with psyhiatric disorders other than schizophrenia were excluded from the study. Patients with a history of neurological or medical disorder that might affect neuropsychological function (seizures, head trauma, stroke, brain tumor, meningitis, etc.) or with a recent history of alcohol abuse or psychoactive drugs were also excluded from the study. In addition, control subjects control subjects with the diagnosis of any physical or psychiatric health problems were excluded from the study. Control subjects had no history of physical health problem.

\section{Polymorphism analysis}

DNA was extracted from white blood cells using the method of Miller et al.22. GNB3-C825T, and GNAS1-T393C genotypes were determined using the PCR-RFLP method. We used for the GNB3-C825T polymorphism, sense primer 5'- TGACCCACTTGCCACCCGTGC -3' and antisense primer 5'- GCAGCAGCCAGGGCTGGC -3'; for the GNAS1-T393C polymorphism, sense primer 5'- CTCCTAACTGACATGGTGCAA-3'and antisense primer 5'- TAAGGCCACACAAGTCGGGGT -3' (Invitrogen, Carlsbad, CA, USA). The PCR mixture contained $100 \mathrm{ng}$ DNA template, $0.5 \mu \mathrm{M}$ of each primer, $1.5 \mathrm{mM} \mathrm{MgCl}, 2 \mathrm{mM}$ dNTPs (Invitrogen) and $1 \mathrm{U}$ Taq DNA polymerase (Intron Bio, Sungnam, Kyungki-Do, Korea). After denaturing the DNA for $5 \mathrm{~min}$ at $94^{\circ} \mathrm{C}$, the reaction mixture was subjected to 35 cycles of denaturing for 1 min at $94{ }^{\circ} \mathrm{C}, 45 \mathrm{~s}$ annealing at $60^{\circ} \mathrm{C}$ and $1 \mathrm{~min}$ extension at $72^{\circ} \mathrm{C}$ for the GNB3-C825T. The 268-bp PCR product was digested with BseDI restriction endonuclease and the digested products were separated by electrophoresis on a 3\% agarose gel (UltraPure Agarose; Invitrogen, Carlsbad, CA) and visualized using ethidium bromide. The C/C genotype contains a unique restriction site that results in 152 - and 116-bp products, and the T/T genotype is not cut (268-bp), allowing the GNB3-C825T genotype to be determined. For the GNAS1-T393C polymorphism, the reaction mixture was subjected to 35 cycles of denaturing for $30 \mathrm{~s}$ at $94^{\circ} \mathrm{C}, 45 \mathrm{~s}$ annealing at $58^{\circ} \mathrm{C}$ and 1 min extension at $72^{\circ} \mathrm{C}$. The PCR product ( $345 \mathrm{bp}$ ) was digested with BseGI and the digested products were separated and identified as above. Allele T contained no BseGI site whereas $\mathrm{C}$ contained the BseGI site, giving rise to 259 - and 86 -bp products. Each gel was read by two observers unaware of the subject's status. The reactions were repeated for avoiding any possible conflicts.

\section{Statistical analysis}

Statistical analyses were performed using the Statistical Package for the Social Sciences (SPSS) software package (revision 11.5 SPSS Inc., Chicago, IL, U.S.A.). Data were expressed as mean \pm SD. Differences in the distribution of genotypes or alleles of DNA repair gene between cases and controls were tested using the Chi-square statistic. Linkage disequilibrium among DNA repair gene polymorphisms was assessed using D' and $\mathrm{r}^{2}$ values obtained through the haploview program (http://www.broad.mit.edu/mpg/haploview/documentation.php). $\mathrm{P}$ value $<0.05$ was considered statistically significant.

\section{Results}

Control subjects, and patients were adjusted for age, and sex. Table 1 shows the characteristics of the patients and control groups. The number of smokers was higher in the patient group compared with the numbers in the control group (P: 0.003), and the number of alcohol consumers was higher among the control group compared with number in the patient group $(\mathrm{P}<0.001)$.

There were statistically significant differences in GNB3-C825T genotypes between the controls, and patients $\left(\chi^{2}: 7.52 ; \mathrm{p}: 0.023\right)$. However, there were no significant differences for GNB3-C825T allele frequencies between the schizophrenia patients, and controls $(\mathrm{p}>0.05)$ (Table 2).

Frequencies of GNB3-C825T T+ genotype were higher among the controls compared with the frequencies in patients which demonstrating a protective role of $\mathrm{T}+$ genotype against schizophrenia (p: $0.011, \chi^{2}: 6.39$, OR: $0.466,95 \%$ CI: $0.25-0.84$ ).

Frequencies of GNB3-C825T CC genotype in patients were higher compared with the frequencies in the controls. The individuals having GNB3-C825T CC genotype had 2 fold increased risk for schizophrenia (p: 0.011, $\chi^{2}: 6.39$, OR: $2.14,95 \%$ CI: 1.18-3.90).

Individuals carrying GNB3-C825T TC genotype had decreased risk for schizophrenia (p: $0.011, \chi^{2}: 6.48$, OR: $0.483,95 \%$ CI: $0.27-$ $0.84)$. Frequencies of TC genotype in controls were higher than the frequencies in patients.

However, we found no significant differences for GNAS1-T393C genotype and allele frequencies between schizophrenia patients, and controls $(\mathrm{p}>0.05)$ (Table 2).

While GNB3-C825T CC genotype was associated with schizophrenia in univariate analysis, GNB3-C825T CC genotype was also associated with this disease in multivariate logistic regression analysis by adjusting sex, and age (Table 3 ).

Table 1. Characteristics of the schizophrenia patients and control groups

\begin{tabular}{|l|c|c|c|c|c|c|}
\hline & Controls & Patients & $\mathrm{P}$ & $\mathrm{X}^{2}$ & $\mathrm{OR}$ & $95 \% \mathrm{Cl}$ \\
\hline Age & $40.54 \pm 12.83$ & $41.25 \pm 10.98$ & 0.675 & - & - & - \\
\hline Sex (male/female) & $49 / 51$ & $48 / 52$ & 0.887 & 0.02 & 1.04 & $0.59-1.82$ \\
\hline Smoking (\%, yes/no) & $44.0 / 56.0$ & $65.0 / 35.0$ & 0.003 & 8.89 & 2.36 & $1.33-4.17$ \\
\hline Alcohol (\%, yes/no) & $18.0 / 82.0$ & $1.0 / 99.0$ & 0.000 & 16.8 & 0.046 & $0.006-0.35$ \\
\hline
\end{tabular}


Table 2. The distribution of GNAS1-T393C and GNB3-C825T genotype frequencies in the patient and control groups

\begin{tabular}{|l|c|c|}
\hline GNAS1 -T393C Genotypes & $\begin{array}{c}\text { Controls } \\
\text { n: } 100\end{array}$ & $\begin{array}{c}\text { Patients } \\
\text { n: } 100\end{array}$ \\
\hline TT & $40(40 \%)$ & $38(38 \%)$ \\
\hline CC & $13(13 \%)$ & $12(12 \%)$ \\
\hline TC & $47(47 \%)$ & $50(50 \%)$ \\
\hline ALLELES & & $126(63 \%)$ \\
\hline T & $127(63.5 \%)$ & $74(37 \%)$ \\
\hline C & $73(36.5 \%)$ & $17(17 \%)$ \\
\hline GNB3- C825T GENOTYPES & & $43(43 \%)$ \\
\hline TT & $16(16 \%)$ & $40(40 \%)$ \\
\hline CC & $26(26 \%)$ & $74(37 \%)$ \\
\hline TC & $58(58 \%)$ & $126(63 \%)$ \\
\hline ALLELES & & \\
\hline T & $90(45 \%)$ & \\
\hline C & $110(55 \%)$ & \\
\hline
\end{tabular}

Table 3. The results of multivariate logistic regression analysis

\begin{tabular}{|l|c|c|c|c|c|c|c|}
\hline Variables in the Equation & B & S.E. & Wald & Sig. & Exp (B) & \multicolumn{2}{|c|}{$95 \%$ Cl for EXP(B) } \\
\cline { 3 - 8 } & & & & & 1.007 & Lower & 0.983 \\
\hline Age & 0.007 & 0.012 & 0.322 & 0.571 & 0.946 & 0.535 \\
\hline Sex & -0.056 & 0.290 & 0.037 & 0.847 & 0.031 \\
\hline GNB3-C825T CC & -0.773 & 0.305 & 6.405 & 0.011 & 0.462 & 0.254 & 0.840 \\
\hline
\end{tabular}

Variable(s) entered on step 1: Age, sex, GNB3-C825T CC genotype.

\section{Discussion}

Imbalances of regulatory apoptotic proteins have associations with various diseases in addition to their association with cancer. Some researchers have reported a link between apoptosis and schizophrenia, which was based on the changes of some apoptotic protein levels in different brain areas of schizophrenic patients ${ }^{23}$. Due to this regulation, G-protein and its subunits become a question for schizophrenia by its transductional mechanisms and its critical role for the regulation of programmed cell death ${ }^{24}$. These findings logically might point out a link between G-proteins, and schizophrenia. Therefore, we hypothesized that the genes encoding for G-protein subunits might have a relation and be nominated as a candidate for schizophrenia.

In our research, our findings have showed the positive association of GNB3 gene variants as a risk factor for schizophrenia. In addition, the frequency of CC genotype in GNB3 was more prevalent in patients in contrast to controls. Moreover, we found that the frequencies of T + and TC genotype of GNB3 gene were common in controls than the frequencies in patients. Researchers showed in a previous study that GNB3-C825T polymorphism was associated with treatment response in various antipsychotic drugs that support the aim of our study about the relation $G$ protein and schizophrenia especially for the people receiving pharmacological treatment ${ }^{25}$. TT genotype or T allele carriers of C825T polymorphism were found to be associated with treatment response to serotonin selective reuptake inhibitors (SSRI) in the treatment of depression ${ }^{25}$. Supporting these data, we have found that $\mathrm{T}+$ and $\mathrm{TC}$ genotype might have a protective role in schizophrenia with our patient scale. This results need to be improved and supported with further analyses by studying with larger scale.

Researchers reported that increased efficacy of GNAS1 signaling is observed in striatum and mononuclear leukocytes in schizophrenia patients ${ }^{26}$. In addition, the T393C polymorphism in GNAS1 was shown to be genetically linked to deficit schizophrenia in an Italian population sample, such that the 393TT genotype was observed significantly more in these patients $(37.1 \%)$ than the controls $(22.8 \%)^{27}$. Supporting this, the 393TT genotype appears to increase GNAS mRNA expression, as measured in bladder tumors and adipose tissue of patients suffering from transitional cell carcinoma ${ }^{28}$. On the other hand, we found no significant differences for GNAS1T393C genotype and allele frequencies between schizophrenia patients, and controls ${ }^{14}$. We suggested that G-protein subunit Gas (also known as GNAS1) may be one of the molecules for contributing to the pathophysiology of schizophrenia.

In conclusion, our findings suggested that GNB3-C825T polymorphism might be associated with schizophrenia and with its underlying mechanism. To understand the main impact and capacity for schizophrenia, further studies with larger sample groups are required to clarify the role of $\mathrm{G}$ protein genes for schizophrenia.

\section{Acknowledgement}

This work was supported by the Research Fund of Istanbul University. (Project No: 11081).

\section{Disclosure}

The authors report no conflicts of interest.

\section{References}

1. Carpenter JWT, Buchanan RW. Medical progress: schizophrenia. N Engl J Med. 1994;330:681-90.

2. Nimgaonkar VL, Fujiwara TM, Dutta M, Wood J, Gentry K, Maendel S, et al. Low prevalence of psychoses among the Hutterites, an isolated religious community. Am J Psychiatry. 2000;157(7):1065-70.

3. Jablensky AV and Kalaydjieva LV. Genetic epidemiology of schizophrenia: phenotypes, risk factors, and reproductive behavior. Am J Psychiatry. 2003;160(3):425-9.

4. McGrath J, Saha S, Chant D, Welham J. Schizophrenia: a concise overview of incidence, prevalence, and mortality. Epidemiol Rev. 2008;30:67-76.

5. Messias E, Chen CY, Eaton WW. Epidemiology of schizophrenia: review of findings and myths. Psychiatr Clin North Am. 2007;30(3):323-8.

6. Lee HJ, Cha JH, Ham BJ, Han CS, Kim YK, Lee SH, et al. Association between a G-protein beta 3 subunit gene polymorphism and the symptomatology and treatment responses of major depressive disorders. Pharmacogenomics J. 2004;4(1):29-33. 
7. Mirnics K, Middleton FA, Stanwood GD, Lewis DA, Levitt P. Disease-specific changes in regulator of G-protein signaling 4 (RGS4) expression in schizophrenia. Mol. Psychiatry. 2001;6(3):293-301.

8. Jarskog LF, Glantz LA, Gilmore JH, Lieberman JA. Apoptotic mechanisms in the pathophysiology of schizophrenia. Prog Neuropsychopharmacol Biol Psychiatry. 2005;29(5):846-58.

9. Kovoor A, Seyffarth P, Ebert J, Barghshoon S, Chen CK, Schwarz S, et al. D2 dopamine receptors colocalize regulator of G-protein signaling 9-2(RGS9-2) via the RGS9 DEP domain, and RGS9 knock-out mice develop dyskinesias associated with dopamine pathways. J Neurosci. 2005;25(8):2157-65.

10. Schreiber G, Avissar S. Application of G-proteins in the molecular diagnosis of psychiatric disorders. Expert Rev Mol Diagn. 2003;3(1):69-80.

11. Frey UH, Eisenhardt A, Lummen G, Rubben H, Jockel KH, Schmid KW, et al. The T393C polymorphism of the G alpha s gene (GNAS1) is a novel prognostic marker in bladder cancer. Cancer Epidemiol Biomarkers Prev. 2005;14(4):871-7.

12. Jarskog LF, Selinger ES, Lieberman JA, Gilmore JH. Apoptotic proteins in the temporal cortex in schizophrenia: high $\mathrm{Bax} / \mathrm{Bcl}-2$ ratio without caspase-3 activation. Am J Psychiatry. 2004;161(1):109-15.

13. Siffert W, Rosskopf D, Siffert G, Busch S, Moritz A, Erbel R, et al. Association of a human G-protein beta3 subunit variant with hypertension. Nat Genet. 1998;18(1):45-8.

14. Lee HJ, Kang SG, Paik JW, Lee MS, Cho BH, Park YM, et al. No evidence for an association between $\mathrm{G}$ protein beta3 subunit gene $\mathrm{C} 825 \mathrm{~T}$ polymorphism and tardive dyskinesia in schizophrenia. Hum Psychopharmacol. 2007;22(8):501-4.

15. Willeit M, Praschak-Rieder N, Zill P, Neumeister A, Ackenheil M, Kasper $\mathrm{S}$, et al. C825T polymorphism in the G protein beta3-subunit gene is associated with seasonal affective disorder. Biol Psychiatry. 2003;54(7):682-6.

16. American Psychiatric Association. Diagnostic and statistical manual of mental disorder. 4th ed. Washington, DC: American Psychiatric Press; 1994.

17. First MB, Spitzer RL, Williams JBW. Structured Clinical Interview for DSM-IV SCID-I). Washington, DC: American Psychiatric Association; 1997.
18. Overall JE, Gorham DR. The Brief Psychiatric Rating Scale. Psychol Rep. 1962;10(3):799-812.

19. Ventura J, Nuechterlein KH, Subotnik KL, Gutkind D, Gilbert EA. Symptom dimensions in recent-onset schizophrenia and mania: a principal components analysis of the 24-item Brief Psychiatric Rating Scale. Psychiatry Res. 2000;97(2-3):129-35.

20. Andreasan NC. Methods for assessing positive and negative symptoms. Mod Probl Pharmacopsychiatry. 1990;24:73-88.

21. Endicott J, Spitzer RL. A diagnostic interview: the schedule for affective disorders and schizophrenia. Arch Gen Psychiatry. 1978;35(7):837-44.

22. Miller SA, Dykes DD, Polesky HF. A simple salting out procedure for extracting DNA from human nucleated cells. Nucleic Acids Res. 1988;16(3):1215.

23. Jarskog LF, Gilmore JH, Selinger ES, Lieberman JA. Cortical bcl-2 protein expression and apoptotic regulation in schizophrenia. Biol Psychiatry. 2000;48(7):641-50.

24. Dhanasekaran N, Tsim ST, Dermott JM, Onesime D. Regulation of cell proliferation by G proteins. Oncogene. 1998;17(11 Reviews):1383-94.

25. Müller DJ, De Luca V, Sicard T, King N, Hwang R, Volavka J, et al. Suggestive association between the C825T polymorphism of the G-protein beta3 subunit gene (GNB3) and clinical improvement with antipsychotics in schizophrenia. Eur Neuropsychopharmacol. 2005;15(5):525-31.

26. Zill P, Baghai TC, Zwanzger P, Schule C, Minov C, Riedel M, et al. Evidence for an association between a G-protein beta3-gene variant with depression and response to antidepressant treatment. Neuroreport. 2000;11(9):1893-7.

27. Memo M, Kleinman JE, Hanbauer I. Coupling of dopamine D1 recognition sites with adenylate cyclase in nuclei accumbens and caudatus of schizophrenics. Science. 1983;221(4617):1304-7.

28. Minoretti P, Politi P, Coen E, Di Vito C, Bertona M, Bianchi M, et al The T393C polymorphism of the GNAS1 gene is associated with deficit schizophrenia in an Italian population sample. Neurosci Lett. 2006;397(12):159-63. 